\title{
Plasma melatonin profiles of Romney Marsh sheep in natural photoperiod and in acutely extended darkness
}

\author{
C. D. Matthews, R. F. Seamark and M. V. Guerin \\ Department of Obstetrics and Gynaecology. The University of Adelaide, The Queen Elizabeth \\ Hospital, Woodville, 5011, South Australia
}

\begin{abstract}
Summary. Plasma melatonin was measured at the summer and winter solstices and the autumn and spring equinoxes in Romney Marsh sheep held under natural conditions in South Australia $\left(35^{\circ} \mathrm{S}\right)$. The amount of melatonin detected was generally related to the extent of natural darkness, though the melatonin onset was particularly delayed after dusk in winter compared with other seasons. The duration of detectable melatonin was shorter in summer than at any other season.

After each initial $24 \mathrm{~h}$ sampling, the sheep were resampled for a further $24 \mathrm{~h}$ in acutely extended darkness to mark the phase and duration of suprachiasmatic nuclei activity which is believed to be the source of the melatonin signal. The onset of high plasma melatonin was earlier than the time of natural sunset in spring and summer, but not different from the time of natural sunset in autumn and winter. The offset of high plasma melatonin was later than the time of natural sunrise at all times of year and particularly so in summer. Under the extended dark conditions, the duration of detectable melatonin was longer than that under natural photoperiod at all seasons of the year and the duration of melatonin was again shorter in summer than winter.

If melatonin measurements under the conditions of extended darkness do reflect the phase and duration of suprachiasmatic nuclei function then the natural light of the photoperiod can, particularly during long photoperiod conditions, mask the expression of the pacemaker. The findings may have implications for the timing of the breeding season in Romney Marsh sheep.
\end{abstract}

Ke!words: melatonin; suprachiasmatic nuclei; seasonal breeding; sheep

\section{Introduction}

The on-off signal for melatonin secretion from the pineal gland is believed to originate in the suprachiasmatic nucleus of the hypothalamus (Moore \& Klein, 1974; Lincoln et al., 1985). Suprachiasmatic nuclear neurons have been shown to have an endogenous circadian (about $24 \mathrm{~h}$ ) rhythm in electrical (Inouye \& Kawamura, 1979) and metabolic activity (Schwartz et al., 1980) but are subject to the influence of the light-dark cycle. Light on the retina increases metabolic activity in the suprachiasmatic nucleus inhibiting central sympathetic function (Nischino et al., 1976), pineal enzyme activity (Moore \& Klein, 1974) and suppressing melatonin (Rollag \& Niswender, 1976; Illnerova et al., 1978; Lewy et al., 1980). Thus, the suprachiasmatic nuclei acts as an endogenous pacemaker responsible for rhythmic melatonin secretion, but is subject to entrainment (phase shifting) effects of the environmental light-dark cycle (Ravault et al., 1989). However, since light has the potential for masking (gating) effects in addition to entraining effects on the pacemaker, just how accurately melatonin secretion, as measured in natural photoperiod, reflects the true circadian activity of the pacemaker is uncertain (Lincoln et al., 1985). Certainly, under artificial light-dark 
conditions, melatonin secretion in sheep is extremely sensitive to light suppression (Arendt \& Ravault, 1988).

The possibility that suppressive effects of natural light occur at dusk and dawn was examined by determining melatonin profiles in Romney Marsh sheep under natural photoperiod and then under acutely extended dark conditions at regular intervals throughout the year.

\section{Materials and Methods}

\section{Animals and treatments}

Animal experiments were performed in 1987 with eight 2-year-old Romney Marsh ewes maintained under natural environmental conditions at the Waite Institute, South Australia $\left(35^{\circ} \mathrm{S}\right)$, except during the $48 \mathrm{~h}$ of intensive bleeding. During sampling the sheep were initially penned for $24 \mathrm{~h}$ in an open-sided shed with continuous access to natural light for the initial $24 \mathrm{~h}$ of sampling and then moved to a well-ventilated dark room for a further $24 \mathrm{~h}$, to sample under extended dark conditions. Water and food were provided ad libitum. Bleeding was by an indwelling jugular catheter (14G IV Abbott Drum Cartridge 4719 Abbott, Ireland) and the catheter was flushed regularly with isotonic saline containing heparin $500 \mathrm{iu} \mathrm{l}^{-1}$ (Baxter Healthcare, Australia) and $600 \mathrm{mg}$ benzyl penicillin $\mathrm{I}^{-1}$ (Commonwealth Serum Labs. Australia). Bleeding during the dark period was performed using a red safe-light. Blood samples were obtained every 20 min during the hours surrounding natural dusk and dawn and every $30 \mathrm{~min}$ during the remaining period, and plasma was stored frozen until assay. Sampling was perfomed within 6 days of the summer and winter solstices and the autumn and spring equinoxes. For studies in extended darkness (the next $24 \mathrm{~h}$ ), the sheep were placed in total darkness ( $<1$ lux $) 5 \mathrm{~h}$ before natural sunset and $5 \mathrm{~h}$ after natural sunrise. The immediate (within $24 \mathrm{~h}$ ) expansion of darkness at sunset and sunrise was designed to unmask any suppressive effects of light and to avoid any possibility of change of circadian suprachiasmatic nuclear activity through entrainment (phase alteration). All clock time determinations were corrected for local summer time changes and, therefore, are based on natural photoperiod. Official meteorological data were used to define the times of natural sunset and sunrise. The difference between first (last) light and the time of sunrise (sunset) varies by less than 10 min throughout the year at this latitude.

\section{Measurement of melatonin}

Melatonin was assayed in duplicate with $20 \mu$ laliquots using the method of Kennaway (1982). Recovery on spiked serum samples at 300 and $1500 \mathrm{fmol} \mathrm{m}^{-1}$ used as quality controls was 87.2 and $89 \cdot 1 \%(n=8)$, respectively. The intra-assay coefficients of variation over repeated measurements at 120,300 and $1500 \mathrm{fmol} \mathrm{ml}^{-1}$ were $16.7(n=14)$, $10.5(n=11)$ and $2.9 \%(n=6)$, respectively. The interassay coefficients of variation over the course of the assays at similar concentrations were $10 \cdot 6(n=14), 11 \cdot 5(n=11)$ and $4.8 \%(n=6)$, respectively. The sensitivity of each assay was calculated at $95 \%$ of the zero standard and the mean sensitivity $( \pm$ SEM) of the assays were $77 \cdot 1( \pm 24 \cdot 2)$ (December study), $75.4( \pm 23.3)$ (March), $64.4( \pm 14.5)$ (June) and 51.0 $( \pm 10.6) \mathrm{fmol} \mathrm{ml}^{-1}$ (October). All samples from individual sheep (either onset or offset) at a particular time of year were measured in the same assay. The onset (and offset) of the melatonin rhythm was defined as the initial sample containing detectable (absent) melatonin above (below) mean assay sensitivity providing the subsequent $2 \times 20 \mathrm{~min}$ samples sustained the rise (or absence).

\section{Statistical analysis}

The times of onset, offset and duration of melatonin secretion in both natural photoperiod and extended darkness at and between each season were individually analysed by separate ANOVA with repeated measurements (Table 1). The comparison of onset and sunset times, offset and sunrise times and duration and dark period was carried out by hypothesis testing for a population mean (Woolson, 1987). The null hypothesis was that they are equal. SAS (SAS Institute Inc., version 6.03) package was used for two-way analysis.

\section{Results}

Natural annual changes in photoperiod at $35^{\circ} \mathrm{S}$ show a variation in duration of $14.5 \mathrm{~h}$ daylight (summer) to $9.8 \mathrm{~h}$ (winter) (meteorological tables). All animals demonstrated diurnal patterns of melatonin excretion, detectable values during the dark period being well above the assay sensitivity. Mean peak amplitude values recorded were $350 \mathrm{fmol} \mathrm{ml}^{-1}$, no differences being noted in amplitude between seasons, or between the two experimental conditions, natural and acutely extended darkness. 
Table 1. Relationships between presence of melatonin in plasma in sheep and onset, offset and durations of natural photoperiod and of the experimental conditions of extended darkness throughout the year

\begin{tabular}{|c|c|c|c|c|}
\hline & Summer & Autumn & Winter & Spring \\
\hline Time of sunset/sunrise & $19: 30 / 05: 00$ & $18: 26 / 06: 20$ & $17: 11 / 07: 23$ & $18: 18 / 05: 55$ \\
\hline Duration of darkness & $9 \cdot 5$ & 11.9 & $14 \cdot 2$ & $11 \cdot 6$ \\
\hline \multicolumn{5}{|l|}{ Natural photoperiod } \\
\hline Time of onset \pm SEM & $20: 18 \pm 0 \cdot 2^{b}$ & $19: 12 \pm 0 \cdot 1^{a}$ & $19: 18 \pm 0.6$ & $19: 12 \pm 0 \cdot 2^{a}$ \\
\hline Sunset & $P<0.01$ & $P<0.001$ & $P<0.001$ & $P<0.001$ \\
\hline Time of offset \pm SEM & $05: 36 \pm 0 \cdot 5^{a, c}$ & $06: 48 \pm 0 \cdot 2^{a, d}$ & $07: 36 \pm 0 \cdot 1^{b}$ & $06: 24 \pm 0 \cdot 3^{\mathrm{a}}$ \\
\hline Sunrise & ns & $P<0.05$ & $P<0.05$ & $\mathrm{~ns}$ \\
\hline \multicolumn{5}{|l|}{ Extended darkness } \\
\hline Time of onset \pm SEM & $18: 30 \pm 0 \cdot 5^{b}$ & $17: 42 \pm 0 \cdot 5^{\mathrm{b}}$ & $17: 30 \pm 0.5$ & $16: 30 \pm 0 \cdot 1^{a}$ \\
\hline Sunset & $P<0.01$ & ns & ns & $P<0.001$ \\
\hline Natural onset & $P<0.001$ & $P<0.05$ & $P<0.05$ & $P<0.001$ \\
\hline Time of offset \pm SEM & $07: 18 \pm 0 \cdot 3$ & $07: 24 \pm 0 \cdot 2$ & $08: 12 \pm 0 \cdot 4$ & $07: 18 \pm 0.5$ \\
\hline Sunrise & $P<0.001$ & $P<0.001$ & $P<0.05$ & $P<0.005$ \\
\hline Natural offset & $P<0.01$ & ns & ns & ns \\
\hline \multicolumn{5}{|l|}{ Natural photoperiod } \\
\hline Duration melatonin & $9 \cdot 3^{\mathrm{f}}$ & $11 \cdot 6^{\mathrm{e}}$ & $12 \cdot 3^{\mathrm{e}}$ & $11 \cdot 2^{\mathrm{e}}$ \\
\hline Dark period & ns & ns & $P<0.05$ & $P<0.05$ \\
\hline \multicolumn{5}{|l|}{ Extended darkness } \\
\hline Duration melatonin & $12 \cdot 8^{\mathrm{f}}$ & $13 \cdot 7$ & $14 \cdot 7^{\mathrm{e}}$ & $14.9^{\mathrm{e}}$ \\
\hline Dark period & $P<0.001$ & $P<0.05$ & ns & $P<0.001$ \\
\hline Natural duration & $P<0.001$ & $P<0 \cdot 01$ & $P<0.005$ & $P<0.001$ \\
\hline
\end{tabular}

${ }^{a}$ Earlier than ${ }^{b}$; ${ }^{c}$ earlier than ${ }^{d}$; ${ }^{e}$ longer than ${ }^{f}$; ns: not significant.

All times and durations in hours.

Under natural conditions the mean time ( \pm SEM) of melatonin onset (Fig. 1) was $2018 \pm 0 \cdot 2$ (summer), $1912 \pm 0.1$ (autumn), $1918 \pm 0.6$ (winter) and $1912 \pm 0.2 \mathrm{~h}$ (spring). All melatonin onset times were later than sunset at all seasons $(P<0.01)$. The delay between the time of sunset and the natural melatonin onset was $0.8 \mathrm{~h}$ (summer and autumn), $2.1 \mathrm{~h}$ (winter) and $0.9 \mathrm{~h}$ (spring). The delay in winter was greater than at any other season $(P<0 \cdot 05)$.

\section{Summer}

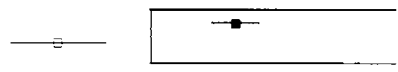

Autumn
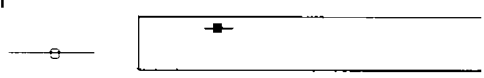

Winter

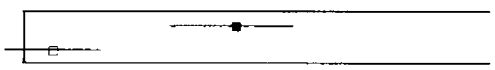

Spring

$\square$

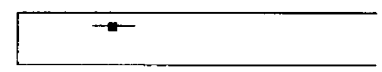

Summer

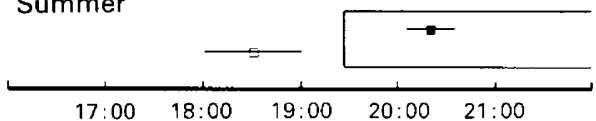

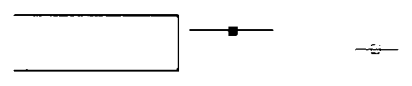
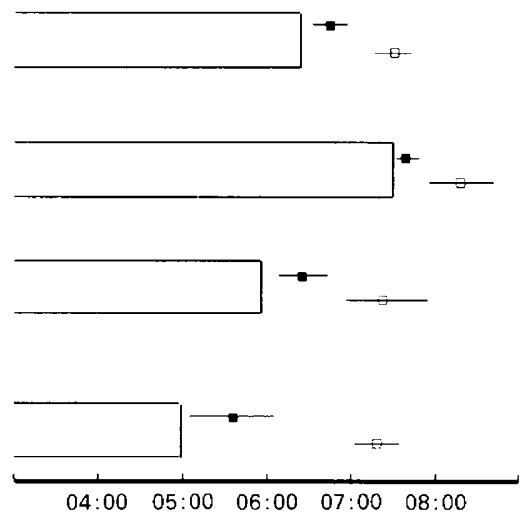

Clock time

Fig. 1. Plasma melatonin onset and offset times ( \pm SEM) in sheep in natural photoperiod $(\boldsymbol{\square})$ and in extended darkness $(\square)$ for the four seasons sampled; the summer result is repeated for continuity. Clock times have been adjusted for periods of daylight saving. 
Melatonin offset times in natural conditions occurred after sunrise in autumn and winter $(P<0.05)$ and varied with the time of year, $0536 \pm 0.5 \mathrm{~h}$ (summer), $0648 \pm 0.2 \mathrm{~h}$ (autumn), $0736 \pm 0.1 \mathrm{~h}$ (winter) and $0624 \pm 0.3 \mathrm{~h}$ (spring). Mean offset times showed less variation with respect to the time of dawn $(0 \cdot 4 \mathrm{~h}$, range $0 \cdot 2-0 \cdot 6)$ than melatonin onset times did to the time of natural dusk $(1 \cdot 4 \mathrm{~h}$, range $0 \cdot 8-2 \cdot 2)$.

The duration of the detectable melatonin secretion under conditions of natural photoperiod was shorter in summer than at any other season $(P<0.05)$. Mean durations were winter $(12.3 \mathrm{~h})$ and summer $(9 \cdot 3 \mathrm{~h})$, with intermediate durations in autumn $(11.6 \mathrm{~h})$, and spring $(11.2 \mathrm{~h})$; thus the deficit between the official times of night and the duration of increased melatonin secretion was $0.2 \mathrm{~h}$ (summer), $0.3 \mathrm{~h}$ (autumn), $1.9 \mathrm{~h}$ (winter) and $0.4 \mathrm{~h}$ (spring), a deficit of $<30 \mathrm{~min}$ except during winter (114 min).

At all times of year under conditions of extended darkness an advance in the time of onset of melatonin secretion was evident compared with that seen under natural photoperiod $(P<0 \cdot 05)$. The mean differences between melatonin onset under natural conditions and the time of melatonin rise under conditions of extended darkness were $1.8 \mathrm{~h}$ (summer), $1.6 \mathrm{~h}$ (autumn), $1.8 \mathrm{~h}$ (winter) and $2.7 \mathrm{~h}$ (spring). Onset times under extended dark conditions in spring and summer were earlier than sunset $(P<0.001$ and $P<0.01$, respectively). In winter and autumn the onset times under extended darkness were not different to the time of dusk.

The time of offset of melatonin secretion in extended darkness was later than sunrise at all seasons $(P<0.05)$ and later than the melatonin offset in natural conditions in summer (a delay of $1.7 \mathrm{~h}, P<0.01)$ and spring $(0.9 \mathrm{~h}, P<0.05)$. The duration of the melatonin secretion under extended darkness was greater than the duration of the rhythm in natural conditions at all times of year $(P<0.01)$ and longer in winter $(14.7 \mathrm{~h})$ than summer $(12.8 \mathrm{~h})(P<0.05)$. Thus the mean time of melatonin secretion under conditions of extended darkness was greater than the secretion under natural photoperiod by $3.5 \mathrm{~h}$ (summer), $2.1 \mathrm{~h}$ (autumn), $2.4 \mathrm{~h}$ (winter) and $3.7 \mathrm{~h}$ (spring) and greater than the duration of the night by $3 \cdot 2 \mathrm{~h}$ (summer), $1.9 \mathrm{~h}$ (autumn), $1.3 \mathrm{~h}$ (winter) and $3 \cdot 2 \mathrm{~h}$ (spring).

The results indicate that during the long day lengths of spring and summer the plasma melatonin signal is shaped to a shorter profile by a suppressive effect of light since the provision of extended darkness at this time will unmask a longer melatonin signal.

\section{Discussion}

The direct daily effect of natural light on the pacemaker of the suprachiasmatic nuclei appears to be the crucial mechanism to ensure stable entrainment for those animals whose endogenous period $(\tau)$ differs from $24 \mathrm{~h}$ (Pittendrigh, 1981). An indication of the extent of the suppressive effects of light on the pacemaker in humans has been documented by Lewy et al. (1985) using a paradigm of acute dark expansion originally described in rats (Illnerova \& Vanecek, 1982, 1983) and a similar strategy to that used in this study. Under the conditions of acutely extended darkness, melatonin secretion provided different circadian information to that apparent from the measurement of melatonin under natural photoperiod.

The results of this study suggest that the mean increase of plasma melatonin concentration under natural photoperiodic conditions at $35^{\circ} \mathrm{S}$ in Romney Marsh sheep conforms to the changing night length within 30 min except in winter when owing to a delay in the onset of secretion the mean difference is about $2 \mathrm{~h}$. These results suggest that Romney Marsh sheep (like Suffolk ewes, Earl et al., 1990) may have a $\tau$ greater than $24 \mathrm{~h}$; these findings are similar to, but the converse of, the results in Soay rams which appear to have $\tau$ of less than $24 \mathrm{~h}$ (Maeda \& Lincoln, 1990). In general, melatonin offset times were either coincident with (spring and summer) or later than (autumn and winter) dawn. Thus the Romney ewe under the natural photoperiod examined experienced a melatonin duration varying between 9.3 and $12.3 \mathrm{~h}$ through the year, a $3 \mathrm{~h}$ difference compared with the $5 \mathrm{~h}$ change in natural photoperiod. 
In conditions of extended darkness, melatonin onset times were earlier than the rise under natural conditions at all times of year and in summer and spring this onset time was significantly earlier than the time of sunset. Melatonin offset times in extended darkness were not significantly different from the offsets of the natural rhythm except in summer when it was clearly later. The duration of melatonin secretion in extended darkness was significantly longer (about $2-3 \mathrm{~h}$ ) than melatonin secretion in the natural photoperiod at each season except winter. The findings in winter suggest that there is a limit to the duration of melatonin secretion approximating to the duration of the longest night of the year under the entrained conditions of natural photoperiod.

Whether an exact temporal relationship is present between activity and inactivity of the suprachiasmatic nuclei and endogenous melatonin secretion remains to be proven. The most important findings of this study concern the presumed interaction of the onset of suprachiasmatic nuclear function (as measured by melatonin secretion in extended darkness), the time of dusk and the observed natural melatonin secretion. In spring and summer the initiation of change in suprachiasmatic nuclei is earlier than dusk and thus under natural photoperiod conditions natural daylight appears to suppress (inhibit) melatonin secretion at this time of year, whereas in autumn and winter conditions the onset of melatonin secretion is coincident with dusk. Thus, the start of 'activity' of the suprachiasmatic nuclei may be 'illuminated' in spring and summer conditions whereas in autumn and winter the earlier time of dusk precludes any effect of natural light on the nuclei. The advance in the time of onset of melatonin secretion seen at all seasons and the longer signal in winter than in summer in extended dark conditions may indicate that some entrainment effects of the pre-existing photoperiod are still present.

Melatonin has been recognized as playing an important co-ordinating signal for time measurement (Karsch, 1986; Tamarkin et al., 1985), an essential mechanism for timing the breeding season precisely. The administration of melatonin under experimental conditions to pinealectomized (melatonin-free) animals can initially mimic long or short day conditions (Bittman \& Karsch, 1984) and can dominate (Yellon et al., 1985) the reproductive response even in the presence of conflicting photoperiodic information. Pinealectomized or blinded sheep held in natural photoperiod (and not isolated from intact controls) can generally synchronize their annual reproductive activity normally (Clegg et al., 1965; Legan \& Karsch, 1980; Matthews et al., 1981), in contrast to the gradual loss of annual entrainment seen when pinealectomized animals are kept in isolated conditions (Bittman et al., 1983). Melatonin secretion in normal sheep seems to be critical for synchronizing an endogenous mechanism so that appropriate reproductive events are precisely timed to a particular time of year (Herbert, 1981; Hoffmann, 1981). Just how melatonin performs this function is unclear. In sheep and some other species the secretion of melatonin has generally been reported to follow the duration of the dark period (Rollag \& Niswender, 1976; Kennaway et al., 1977; Lincoln \& Short, 1980; Arendt et al., 1981) and this mechanism is believed to underlie the seasonal reproductive response given the longer period of melatonin secretion in winter than summer (Maywood et al., 1990). However, another major hypothesis is centred around the possibility that there is a phase of the circadian cycle sensitive to the presence of melatonin (Tamarkin et al., 1976; Rollag et al., 1978) and the timing of reproductive events depends on the presence or absence of melatonin at this time.

The findings of this study suggest that the coincidence of natural light with 'activity' of the suprachiasmatic nuclei at dusk during the prior spring and summer may serve to sensitize the photoreceptive system so that the decreasing day length of autumn can be registered and breeding occur in response. If this hypothesis is correct then the onset of seasonal oestrus should be delayed if the coincidence of the natural light of dusk in spring and summer with 'activity' of suprachiasmatic nuclei is avoided by either imposing additional darkness at dusk or by allowing the function of the nuclei to phase delay relative to the natural light-dark cycle by additional darkness at dawn. This appears to be the case (M. V. Guerin, A. Napier \& C. D. Matthews, unpublished results). Recent work by Malpaux et al. (1989) under experimental conditions using Suffolk ewes has already demonstrated the importance of long days in the control of the endogenous reproductive rhythm. 
The results of our study under natural conditions are in general agreement and offer a circadian basis for the explanation of the role of long days.

We thank A. J. Lewy for helpful discussions, D. Kennaway for assay methodology, F. Carbone, A. Napier and J. Zeischang for assay assistance and B. Setchell for animal holding facilities at the Waite Agricultural Research Institute. X. Wang and B. Godfrey assisted substantially with the statistical analysis and C. Burford provided secretarial services. The study was supported by a NH and MRC grant to C. D. Matthews and R. F. Seamark.

\section{References}

Arendt, J. \& Ravault, J-P. (1988) Suppression of melatonin secretion in Ile-de-France rams by different light intensities. Journal of Pineal Research 5, $245-250$.

Arendt, J., Symons, A.M. \& Laud, C. (1981) Pineal function in the sheep: evidence for a possible mechanism mediating seasonal reproductive activity. Experientia 37, 584-586.

Bittman, E.L. \& Karsch, F.J. (1984) Nightly duration of pineal melatonin secretion determines the reproductive response to inhibitory day length in the ewe. Biology of Reproduction 30, 585-593.

Bittman, E.L., Karsch, F.J. \& Hopkins, J. (1983) Role of the pineal gland in ovine photoperiodism: regulation of seasonal breeding and negative feedback effects of oestradiol upon LH secretion. Endocrinology 113, 329-336.

Clegg, M.T., Cole, H.H. \& Ganong, W.F. (1965) The role of light in the regulation of cyclical estrous activity in sheep. Miscellaneous Publications, US Department of Agriculture 1005, 96-114.

Earl, C.R., D'Occhio, M.J., Kennaway, D.J. \& Seamark, R.F. (1990) Temporal changes in the pattern of melatonin secretion in sheep held in constant darkness. Journal of Pineal Research 8, 115-121.

Herbert, J. (1981) The pineal gland and photoperiodic control of the ferrets reproductive cycle. In Biological Clocks in Seasonal Reproductive Cycles, pp. 261-276. Eds B. K. Follett \& D. E. Follett. Wiley, NY.

Hoffmann, K. (1981) Photoperiodism in Vertebrates. Handbook of Behavioural Neurobiology 4. Biological Rhy'thms. Ed. J. Aschoff. Plenum Press, New York and London.

Illnerova, H. \& Vanecek, J. (1982) Complex control of the circadian rhythm in $N$-acetyl transferase activity in the rat pineal gland. In Vertebrate Circadian Systems, pp. 285 296. Eds J. Aschoff, S. Daan \& G. Groos. Springer-Verlag, Berlin-Heidelberg.

Illnerova, H. \& Vanecek, J. (1983) Extension of the rat pineal $N$-acetyl transferase rhythm in continuous darkness and on short photoperiod. Brain Research 261, 176-179.

Illnerova, H., Backstrom, M., Saaf, J., Wetterberg, L. \& Vangbo, B. (1978) Melatonin in rat pineal gland and serum: rapid parallel decline after light exposure at night. Neuroscience Letters 9, 189-193.

Inouye, S.T. \& Kawamura, H. (1979) Persistence of circadian rhythmicity in mammalian hypothalamic 'island' containing the suprachiasmic nucleus. Proceedings of the National Academy of Sciences USA 76, 5961--5966.
Karsch, F.J. (1986) A role for melatonin as a timekeeping hormone in the ewe. Journal of Neural Transmitters 21, 109-124.

Kennaway, D.J., Frith, R.G., Phillipou, G., Matthews, C.D. \& Seamark, R.F. (1977) A specific radioimmunoassay for melatonin in biological tissue and fluid and its validation by gas chromatography mass spectrometry. Endocrinology 101, 119-127.

Kennaway, D.J., Gilmore, T.A. \& Seamark, R.F. (1982) Effect of melatonin feeding on serum prolactin and gonadotrophin levels and the onset of estrous cyclicity in sheep. Endocrinology 110, 1766-1772.

Legan, S.J. \& Karsch, F.J. (1980) Importance of retinal photoreceptors to photoperiodic control of seasonal breeding in the ewe. Biology of Reproduction 29, $316-325$.

Lewy, A.J., Wehr, T.A., Goodwin, F.K., Newsome, D.A. \& Markey, S.P. (1980) Light suppresses melatonin secretion in humans. Science 210, 1267-1269.

Lewy, A.J., Sack, R.L. \& Singer, C.M. (1985) Immediate and delayed effects of bright light on human melatonin production: shifting 'dawn' and 'dusk' shifts the dim light melatonin onset (DLMO). The medical and biological effects of light. Annals of the New York Academy of Sciences 453, 253 259.

Lincoln, G.A. \& Short, R.V. (1980) Seasonal breeding, Nature's contraceptive. Recent Progress in Hormone Research 36, 1-52.

Lincoln, G.A., Ebling, F.J.P. \& Almeida, O.F.X. (1985) Generation of melatonin rhythms. Photoperiodism, melatonin and the pineal. Ciba Symposium, Pittman, London 117, 129-148.

Maeda, K-I. \& Lincoln, G.A. (1990) Phase shifts in the circadian rhythm in plasma concentrations of melatonin in rams induced by a I-hour light pulse. Journal of Biological Rhythms 5, 97-106.

Malpaux, B., Robinson, J.E., Wayne, N.L. \& Karsch, F.J. (1989) Regulation of the onset of the breeding season of the ewe: importance of long days and of an endogenous reproductive rhythm. Endocrinology 122, 269-278.

Matthews, C.D., Kennaway, D.J. \& Seamark, R.F. (1981) Reproductive studies in pinealectomised sheep. Pineal Function, pp. 137--142. Eds C. D. Matthews \& R. F. Seamark. Elsevier/North Holland Biomedical Press, Amsterdam, New York, Oxford.

Maywood, E.S., Buttery, R.C., Vance, G.H.S., Herbert, J. \& Hastings, M.H. (1990) Gonadal responses of the male Syrian hamster to programmed infusions of melatonin are sensitive to signal duration and frequency but not to signal phase nor to lesions of the 
suprachiasmatic nuclei. Biology of Reproduction 43, $174-182$.

Moore, R.Y. \& Klein, D.C. (1974) Visual pathways and the central neural control of a circadian rhythm in pineal serotonin $N$-acetyltransferase activity. Brain Research 71, 17-33.

Nischino, H., Koizumi, K. \& Brooks, C.M. (1976) The role of the suprachiasmic nuclei of the hypothalamus in the production of circadian rhythms. Brain Research 112, 45-59.

Pittendrigh, C.S. (1981) Circadian Systems: entrainment. In Handbook of Behavioural Neurobiology Vol. 4, Biological Rhythms, pp. 95-124. Ed. J. Aschoff. Plenum Press, New York.

Ravault, J-P., Arendt, J., Tobler, I., Chesneau, D. \& Maulin, O. (1989) Entrainment of melatonin rhythms in rams by symmetrical light-dark cycles of different period length. Chronobiology International 6, 329-339.

Rollag, M.D. \& Niswender, G.D. (1976) Radioimmunoassay of serum concentrations of melatonin in sheep exposed to different lighting regimens. Endocrinology 98, $482-489$.

Rollag, M.D., O'Callaghan, P.L. \& Niswender, G.D. (1978) Serum melatonin concentrations during different stages of the annual reproductive cycle in ewes. Biology of Reproduction 18, 279-285.
Schwartz, W.J., Davidsen, L.C. \& Smith, C.B. (1980) In Vivo Metabolic Activity of a putative circadian oscillator, the rat suprachiasmic nucleus. Journal of Comparative Neurology 189, 157-167.

Tamarkin, L., Westrom, W.K., Hamill, A.I. \& Goldman, B.D. (1976) Effect of melatonin on the reproductive systems of male and female Syrian hamsters: a diurnal rhythm in sensitivity to melatonin. Endocrinology 99, 1534-1541.

Tamarkin, L., Baird, C.J. \& Almeida, O.F.X. (1985) Melatonin: a co-ordinating signal for mammalian reproduction. Science 227, 714-720.

Woolson, R.F. (1987) Statistical Methods for the Analysis of Biomedical Data. Eds V. Barnett, R. A. Bradley, J. S. Hunter, D. G. Kendall, A. F. M. Smith, S. M. Stigler \& G. S. Watson. J. Wiley and Sons, New York.

Yellon, S.M., Bittman, E.L., Lehman, M.N., Olster, D.H., Robinson, J.E. \& Karsch, F.J. (1985) Importance of duration of nocturnal melatonin secretion in determining the reproductive response to inductive photoperiod in the ewe. Biology of Reproduction 32, 523-529.

Received 9 July 1991 